\title{
Chain Scissions of Rubber Molecules by a Tensile Force in Filled Rubber Systems
}

\author{
Nozomu SuzuKi and Masayoshi Iто* \\ Department of Chemistry, Faculty of Science, Tokyo University of Science, \\ 1-3 Kagurazaka, Shinjuku-ku, Tokyo 162-8601, Japan \\ * Corresponding author: itma56@rs.kagu.tus.ac.jp \\ Received March 25, 2005; Accepted April 16, 2005 \\ (C) 2005 The Society of Rubber Industry, Japan
}

\begin{abstract}
Effects of interfacial interactions between rubber matrix and filler surface on the structural changes of rubber matrix upon a tensile deformation of filled styrene-butadiene rubber (SBR) vulcanizates were studied by ESR and pulsed NMR. The interfacial interactions were controlled by using several kinds of surface modified silicas and carbon blacks. For silica filled systems, the degree of chain scission during tensile deformation of the samples could be evaluated from ESR results. Information on the structural changes of rubber matrix upon a tensile deformation for both carbon black filled and silica filled SBR vulcanizates could be obtained from the results of pulsed NMR. The combination of ESR and NMR results revealed that the degree of chain scission was dependent on the strength of interfacial bondings between filler and rubber molecules and the chain scissions are suggested to occur in the interfacial regions between rubber molecules and fillers.
\end{abstract}

Keywords Filled rubber system, Interfacial interactions, Chain scission, ESR, Pulsed NMR.

\section{Introduction}

The decrease of tensile stress of filled rubber systems which is caused by a prestretching is a well recognized phenomenon known as the Mullins effect ${ }^{1-4)}$. This effect has been attributed to the detachment from the filler surface or slippage on the filler surface, of chains having reached their limit of extensively ${ }^{5,6}$. It is also suggested that the detachment is accompanied by the breaking of rubber to filler bonds ${ }^{5,6}$. However, almost no direct information has been reported on the chain scissions of rubber molecules by the successive stretching cycles of filled rubber systems. During the cyclic deformation of filled rubber systems, the secondary structure formed by the filler might be damaged. The rubber molecules which are anchored to filler particles will break if filler particles have separated enough to stretch the chain to near full elongation. Yatsuyanagi et al. carried out transmission electron microscope (TEM) observations of silica filled vulcanizates before and after the tensile deformation ${ }^{7,8)}$. They found that the secondary structure formed by silica particles was destroyed upon a tensile deformation, with this tendency was more prominent in the system with large secondary structure. Yamaguchi et. al. examined the estimation of the destruction of secondary structure formed by carbon black particles by the changes of electrical resistivity upon a tensile deformation ${ }^{9}$. They suggested that the decrease of electrical resistivity upon a tensile deformation was caused by the destruction of the secondary structure.

Recently, we found that the chain scissions occurred in the silica filled vulcanizates during tensile deformation were successfully detected by ESR technique ${ }^{10)}$. Further, it was found that the degree of chain scission was closely related to the strength of interfacial bonding which was controlled by the coupling agent.

It is well known that the filled rubber systems have multi-component structure depending on the chain mobility of rubber molecules ${ }^{11-13)}$. Information on the chain mobility of each component and the component fraction can be obtained by the pulsed NMR method ${ }^{11-13)}$. Thus, the NMR results are expected to tell us which component will be involved in the chain scissions by a tensile force.

In this study, silica and carbon black filled SBR vulcanizates with different rubber/filler interactions were prepared by using several kinds of silicas and carbon blacks as well as coupling agents. ESR and pulsed NMR 
measurements were carried out for the samples before and after the stretching. Based on the results, effects of rubber/filler interactions on the structural changes of rubber matrix due to chain scissions were studied.

\section{Experimental}

The raw rubber used was a styrene-butadiene rubber (SBR) (Nipol SBR 1502, $M_{\mathrm{w}}=4.3 \times 10^{5}, T_{\mathrm{g}}=-52^{\circ} \mathrm{C}$; Nippon Zeon Co., Japan). The fillers used were two types of precipitated silicas (Nipsil AQ: PR1 and Nipsil ER: PR2, Nippon Silica, Japan) and two types of carbon blacks (N660: CB1 and N326: CB2, Tokai Carbon, Japan). The characteristics of fillers are listed in Table 1. Two kinds of coupling agents were used for the surface modification of silica particles. The one was a mono-functional decyltrimethoxysilane (DS) and the other was a bifunctional bis-(triethoxysilylpropyl)-tetrasulfide (TESPT). The chemical structures of them are listed in Table 2. The reactivity of coupling agents with silanol groups on silica particles depends on the moisture content of silica particles ${ }^{14,15)}$. Thus, as-received silica was dried at $120^{\circ} \mathrm{C}$ under a reduced pressure for $12 \mathrm{~h}$ to minimize the moisture content of silica particles.

Various kinds of composites were prepared by a mechanical mixing. The compositions of them are listed in Table 3. The conditions for the mechanical mixing were as follows; SBR was put into a Banbury mixer (Laboplastomill 50MR; Toyo Seiki, Japan) and masticated under $60 \mathrm{rpm}$ at $60^{\circ} \mathrm{C}$ for $1 \mathrm{~min}$, then dried silica with coupling agent or carbon black was mixed with masticated SBR under $60 \mathrm{rpm}$ at $100^{\circ} \mathrm{C}$ for $1 \mathrm{~min}$. Next, zinc oxide, stearic acid and anti-oxidant were mixed with filled SBR composites at $100^{\circ} \mathrm{C}$ for $2 \mathrm{~min}$. Finally, the masterbatch was mixed with sulfur and accelerator under $60 \mathrm{rpm}$ at $60^{\circ} \mathrm{C}$ for $3 \mathrm{~min}$. The fill factor of the composites at the final stage was set to be $60 \%$. The unvulcanized composites prepared by the mechanical mixing were seated on a roll mill followed by a vulcanization at $160^{\circ} \mathrm{C}$ under a pressure of $400 \mathrm{~kg} / \mathrm{cm}^{2}$. Vulcanization time was $30 \mathrm{~min}$ for silica filled composites and $20 \mathrm{~min}$ for carbon black filled ones, respectively.

Measurements of stress-strain curves were carried out on a tensile tester (IM-20ST; Intesco, Japan) at room temperature $\left(24^{\circ} \mathrm{C}\right)$. The strain rate was $3.0 / \mathrm{min}$.

The ESR spectra were obtained by using an ESR
Table 1. Characteristics of filler particles

\begin{tabular}{rccc}
\hline & $\begin{array}{c}\text { Diameter } \\
(\mathrm{nm})\end{array}$ & $\begin{array}{c}\text { Specific Surface Area } \\
\left(\mathrm{m}^{2} \cdot \mathrm{g}^{-1}\right)\end{array}$ & $\begin{array}{c}N_{\mathrm{SiOH}^{2}}{ }^{2} \\
\left(\mathrm{~nm}^{-2}\right)\end{array}$ \\
\hline Silica PR1 & 18.0 & 187 & 6.0 \\
PR2 & 40.0 & 78.0 & 4.4 \\
Carbon Black CB1 & 60.0 & 26.0 & - \\
CB2 & 27.2 & 83.0 & - \\
\hline
\end{tabular}

${ }^{1)}$ Determined by Nitrogen adsorption.

${ }^{2)}$ Number of silanol groups per unit surface area of silica.
Table 2. Chemical structure of coupling agents

Decyltrimethoxysilane
(DS)

Table 3. Composition of filled rubber systems

\begin{tabular}{|c|c|c|c|c|c|c|c|}
\hline Sample Code & DM-L & DM-H & TM-1 & TM-2 & CF-1 & CF-2 & unfilled \\
\hline SBR & 100 & 100 & 100 & 100 & 100 & 100 & 100 \\
\hline PR1 & 50 & 50 & 50 & - & - & - & - \\
\hline PR2 & - & - & - & 50 & - & - & - \\
\hline CB1 & - & - & - & - & 50 & - & - \\
\hline CB2 & - & - & - & - & - & 50 & - \\
\hline DS & 5.0 & 5.0 & - & - & - & - & - \\
\hline TESPT & - & - & 5.0 & 5.0 & - & - & - \\
\hline Zinc oxide & 3.0 & 3.0 & 3.0 & 3.0 & 3.0 & 3.0 & 3.0 \\
\hline Stearic acid & 2.0 & 2.0 & 2.0 & 2.0 & 2.0 & 2.0 & 2.0 \\
\hline Anti-oxidant $6 \mathrm{C}^{1)}$ & 1.0 & 1.0 & 1.0 & 1.0 & 1.0 & 1.0 & 1.0 \\
\hline Accelerator $\mathrm{CZ}^{2)}$ & 1.0 & 1.0 & 1.0 & 1.0 & 1.0 & 1.0 & 1.0 \\
\hline Accelerator $\mathrm{DPG}^{3)}$ & 1.5 & 1.5 & 1.5 & 1.5 & - & - & - \\
\hline Sulfur & 1.7 & 2.9 & 1.7 & 1.7 & 2.0 & 2.0 & 2.0 \\
\hline
\end{tabular}

${ }^{1)} N$-(1,3-dimethyl butyl)- $N$-phenyl-p-phenylenediamine.

${ }^{2)} \mathrm{N}$-cyclohexyl-2-benzothiazyl-sulfenamide.

${ }^{3)}$ Diphenyl ganidine. 
spectroscopy (ES-FA200, JEOL, Japan) at a resonance frequency of $9.2 \mathrm{GHz}$. The samples for ESR measurements were prepared by the following procedure; the vulcanized sheets were cut into $1 \mathrm{~mm} \times 2 \mathrm{~mm} \times 30 \mathrm{~mm}$. The samples were stretched by a tensile tester at room temperature up to a desired strain (IS: 10-200\%) followed by a release of tensile stress (pre-stretched sample). Then, the prestretched samples were cooled down to $-100^{\circ} \mathrm{C}$ immediately after the release of tensile stress to minimize the change in the number of radicals produced by the tensile deformation. It is reported that the change in the radical concentration becomes negligibly small below $-50^{\circ} \mathrm{C}^{16}$. The ESR measurements for unstretched and prestretched samples were carried out at $-100^{\circ} \mathrm{C}$. The radical concentration in the samples was obtained from a doubleintegration of the first derivative curves of ESR signals by using an aqueous solution of 4-hydroxy-2,2,6,6tetramethylpiperidinooxyl radical (TEMPOL) as an external standard. The g-value and line width were determined by using the 3rd and 4th signals of $\mathrm{Mn}^{2+}$ marker.

Pulsed NMR measurements were carried out with a JEOL pulsed NMR spectrometer (JNM Mu 25, JEOL, Japan), operating at $25 \mathrm{MHz}$. The solid echo sequence provided a good approximation to the free induction decay (FID), from which proton spin-spin relaxation time $\left(T_{2}\right)$ and the fraction of each $T_{2}$ component were obtained. In this study, the width of $90^{\circ}$ pulse and the pulse interval were adjusted to be 1.8 and $12 \mu \mathrm{sec}$, respectively. The samples were stretched by a tensile tester at room temperature up to a desired strain (IS: 10-200\%) followed by a release of tensile stress. The NMR measurements were carried out for unstretched and pre-stretched samples at $30^{\circ} \mathrm{C}$. The spin-spin relaxation time $\left(T_{2}\right)$ and a fraction of each component were determined by fitting the solid echo signal to the Weibull function shown in eq. $(1)^{17)}$;

$$
M(t)=\sum_{i} M_{0 i} \exp \left\lfloor-\left(t / T_{2 i}\right)^{E_{i}}\right\rfloor
$$

where $t$ is the time, $E_{i}$ is the Weibull coefficient, $M_{0 i}$ is the signal intensity at $t$, and $T_{2 i}$ is the spin-spin relaxation time of the $i$ th component. The fraction of the $j$ th component $\left(f_{j}\right)$ is given by

$$
f_{j}=M_{0 j} / \sum M_{0 i}
$$

\section{Results and Discussion}

\section{ESR Results}

Our previous work revealed that the degree of chain scissions of rubber molecules by a tensile force in silica filled vulcanizates could be related to the stress-strain behavior $^{10)}$. It is well recognized that the stress-strain curves at a larger strain for filled rubber systems are affected by the crosslink density of rubber matrix ${ }^{6,8)}$ and rubber/filler interactions ${ }^{8,18)}$. These factors can be controlled by the contents of curing agents and the introduction of coupling agent. The crosslink densities $\left(v_{\mathrm{e}}\right)$ of surface modified silica filled vulcanizates which were determined by a swelling method are shown in Table 4. The combination of data shown in Tables 3 and 4 revealed that the higher the sulfur content, the higher the $v_{\mathrm{e}}$ that could be obtained (DM-L vs. DM-H). In addition, for the same sulfur content, it is seen that the higher $v_{\mathrm{e}}$ was obtained by the introduction of $b i$-functional coupling agent (DM-L vs. TM-1). The $v_{\mathrm{e}}$ for the TM- 2 was higher than that of the TM-1. As shown in Tables 1 and 3, the TM-2 was prepared by using silica with a lower concentration of silanol groups on silica surface. It is recognized that the crosslink reaction of rubber matrix by sulfur is suppressed by silanol groups on silica surface ${ }^{19)}$.

Figure 1 shows the stress-strain curves for unfilled and surface modified silica filled vulcanizates. It is seen that tensile stress at a larger strain was affected by the crosslink

Table 4. Crosslink densities of silica filled vulcanizates

\begin{tabular}{ccccc}
\hline & DM-L & DM-H & TM-1 & TM-2 \\
\hline$v_{\mathrm{e}}\left(10^{4} \mathrm{~mol} \cdot \mathrm{cm}^{-3}\right)$ & 2.62 & 4.07 & 4.98 & 5.47 \\
\hline
\end{tabular}

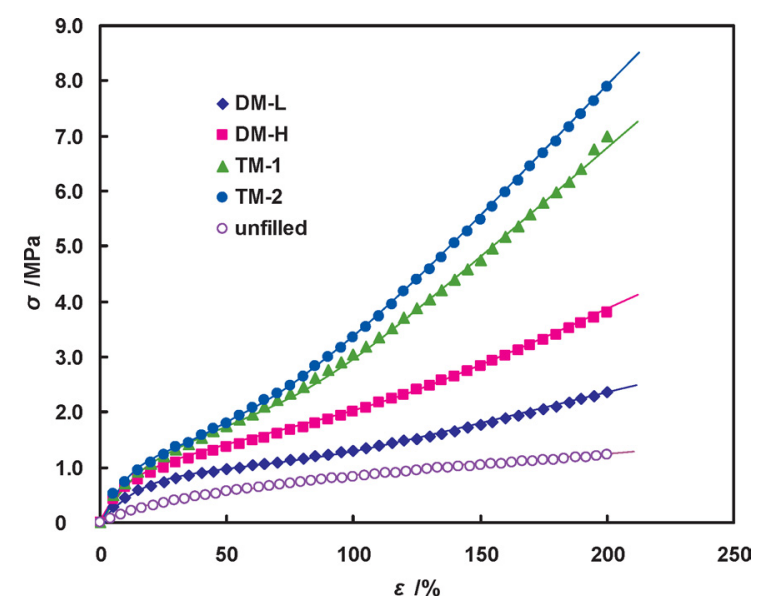

Figure 1. Stress-strain curves at $24^{\circ} \mathrm{C}$ for surface modified silica filled SBR vulcanizates. 
density and the sort of coupling agent. The comparison of the stress-strain curves between the DM-L and DM-H revealed that at a given strain the larger the $v_{\mathrm{e}}$ of the vulcanizate, the larger the tensile stress that could be obtained. However, the stress for both samples was almost leveled off at the large strain region. On the other hand, the tensile stress for the TM-1 and TM-2 steadily increased with increasing the strain, similar to the case of carbon black filled vulcanizates ${ }^{20,21)}$. It is well known that the strong interfacial bondings between carbon black and rubber matrix enhanced the tensile stress at a larger strain $^{20-22)}$. As seen in Table 2, ethoxy groups of TESPT react with silanol groups on silica ${ }^{14,22)}$. In addition, sulfur atoms of TESPT can couple with diene groups of $\mathrm{SBR}^{14,22)}$. Such a chemical structure of TESPT produced a strong chemical bonding between SBR and silica. The evidence of the interfacial bonding between silica and SBR produced by the TESPT could be obtained by TEM observations as shown in our previous report ${ }^{10)}$. On the other hand, the DM has no sulfur atom in the molecular structure, resulted in the no chemical bonding between SBR and silica. Thus, a primary reason for the difference of the tensile behavior between the vulcanizates prepared by using mono- and bi-functional coupling agents is suggested to be caused by the difference of the interfacial bonding.

The first derivative ESR curves for the DM-L (unstretched (a) and pre-stretched (b), (c)) are shown in Fig. 2. All samples showed a broad absorption curve with the g-value of 2.004 and the line width at the maximum slope $\left(\Delta H_{\mathrm{msl}}\right)$ of $1.5 \mathrm{mT}$. It is well known that the line width is affected by the modulation amplitude during the measurement. In this work, this was taken into consideration to determine the line width. As discussed in our previous paper ${ }^{10)}$, the absorption is assigned to the polyenyl radical $\left(-(\mathrm{C}=\mathrm{C})_{n}-\mathrm{C} \cdot\right)^{23-25)}$ formed by the chain scission during sample preparation. The intensity of ESR signals increased with increasing the strain (initial strain: $I S$, (Fig. 2 (b), (c)) without changing the g-value and $\Delta H_{\mathrm{msl}}$. This suggests that the chain scissions occur during the stretching, resulting in the formation of polyenyl radicals. The unstretched sample also showed ESR signal (Fig. 2 (a)).

During the sample preparation by the mechanical mixing, followed by the vulcanization, small amounts of radicals might be produced by the breakage of rubber molecules which were entrapped in the crosslinked network after the vulcanization.

The number of radicals per unit volume of vulcanizates $\left(C_{\mathrm{R}}\right)$ was calculated from ESR spectra. The $C_{\mathrm{R}}$ for the

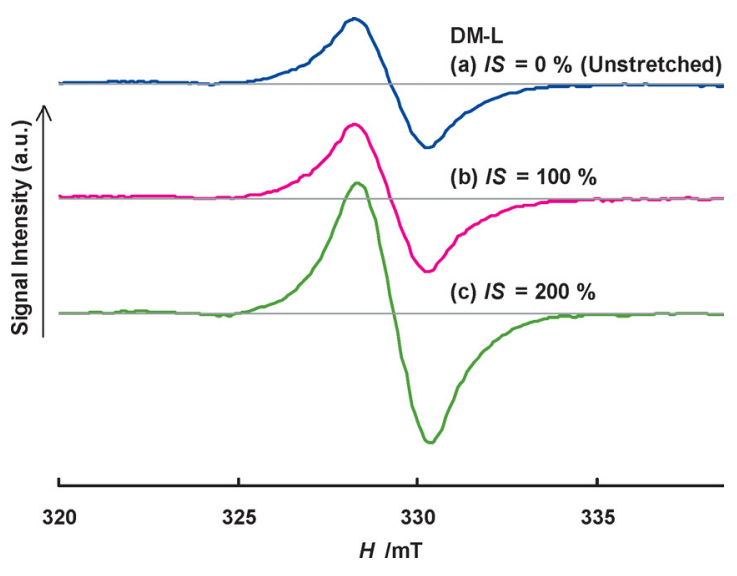

Figure 2. ESR spectra at $-100^{\circ} \mathrm{C}$ for surface modified silica filled SBR vulcanizate (DM-L) with different $I S \mathrm{~s}$.

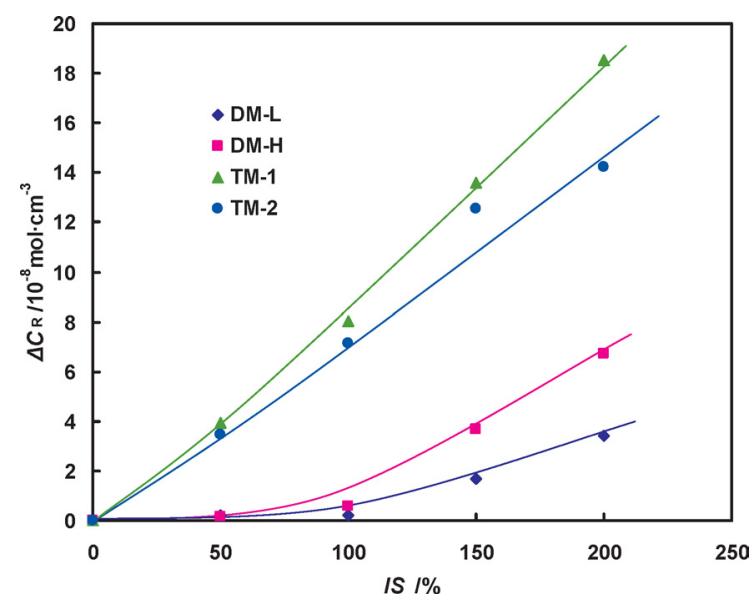

Figure 3. The relation between $I S$ and $\Delta C_{\mathrm{R}}$ for surface modified silica filled SBR vulcanizates.

unstretched sample was $2.6 \times 10^{-8} \mathrm{~mol} \cdot \mathrm{cm}^{-3}$. This value was about ten times larger than that for unfilled SBR vulcanizate. For the preparation of silica filled samples, the mixing torque was considerably higher than that for unfilled samples $\left(\sim 3.0 \times 10^{-9} \mathrm{~mol} \cdot \mathrm{cm}^{-3}\right)$. Thus, the higher $C_{\mathrm{R}}$ value for the unstretched sample might be responsible for the high mixing torque which enhanced the breakage of rubber molecules during the mixing. Also, the $C_{\mathrm{R}}$ for $200 \%$ stretched samples $\left(5.0 \times 10^{-8} \mathrm{~mol} \cdot \mathrm{cm}^{-3}\right)$ was considerably large compared with that for unfilled $200 \%$ stretched samples $\left(\sim 6.0 \times 10^{-9} \mathrm{~mol} \cdot \mathrm{cm}^{-3}\right)$. It is generally accepted that a heterogeneous structure develops in the filler reinforced rubber composites, which enhances the mechanical properties (see Fig. 1). As shown later, the heterogeneous structure is closely related to the degree of chain scission.

The difference of the $C_{\mathrm{R}}$ between pre-stretched and unstretched vulcanizates $\left(\Delta C_{\mathrm{R}}\right)$ was calculated to correlate 
Table 5. $T_{2}{ }^{\prime}$ s for carbon black filled vulcanizate with different $I S \mathrm{~s}$

\begin{tabular}{lcc}
\hline & \multicolumn{2}{c}{$\mathrm{CF}-2$} \\
\cline { 2 - 3 } & $I S=0 \%$ & $150 \%$ \\
\hline$T_{2 \mathrm{~L}}(\mu \mathrm{sec} \pm 3 \%)$ & 639 & 631 \\
$T_{2 \mathrm{M}}(\mu \mathrm{sec} \pm 10 \%)$ & 223 & 218 \\
$T_{2 \mathrm{~S}}(\mu \mathrm{sec} \pm 11 \%)$ & 25.3 & 25.9 \\
\hline
\end{tabular}

with the tensile strain applied to the samples $(I S)$. Figure 3 shows the relation between $I S$ and $\Delta C_{\mathrm{R}}$ for the surface modified silica filled vulcanizates. It is seen that the $\Delta C_{\mathrm{R}}$ for the vulcanizates without interfacial bonding (DM-L and DM-H) was almost zero up to around $I S=100 \%$, followed by slight increase of $\Delta C_{\mathrm{R}}$ with the further increase of the strain. On the other hand, the $\Delta C_{\mathrm{R}}$ for the TM-1 and TM-2 which were prepared by using TESPT increased steadily with increasing the $I S$ even at a small $I S$. Further, $\Delta C_{\mathrm{R}}$ value at a given $I S$ was much larger than that for the vulcanizates without interfacial bonding (DM-l and DM-H). This means that, at a given $I S$, the chain scission is enhanced by the introduction of interfacial bonding. The value of the $\Delta C_{\mathrm{R}}$ for TM-2 was between the TM-1 and the vulcanizates without interfacial bonding (DM-L and DM$\mathrm{H})$. As seen in Table 1, the concentration of silanol groups on silica surface for PR-2 is almost $75 \%$ of PR-1. This suggests that the number of bonding point between silica surface and rubber molecules for TM-2 is small compared with that for TM-1, which might lead to the weaker interfacial bondings. These results suggest that the stronger the interfacial bondings, the larger the degree of chain scission at a given strain that could be observed.

For carbon black filled vulcanizates, we also examined ESR measurements. However, carbon black itself showed an ESR signal arisen from lone electrons in its particle ${ }^{26,27)}$. Further, the intensity of ESR signal for carbon black was much stronger than that for the carbon radicals produced by the chain scission of rubber molecules. These made it difficult to analyze the chain scissions by a tensile force in carbon black filled vulcanizates.

\section{NMR results}

It is well known that the filled rubber vulcanizates have multi-component structure depending on the chain mobility of rubber molecules ${ }^{11-13)}$. A pulsed NMR is a powerful technique to obtain information on the chain mobility in each component and the component fraction of the multi-component systems. For example, carbon black filled SBR vulcanizates exhibited three $T_{2}{ }^{\prime} \mathrm{s}$, the long $T_{2}$ $\left(T_{2 \mathrm{~L}}\right)$, intermediate $T_{2}\left(T_{2 \mathrm{M}}\right)$ and short $T_{2}\left(T_{2 \mathrm{~S}}\right)$, indicating the existence of loosely, intermediately and tightly

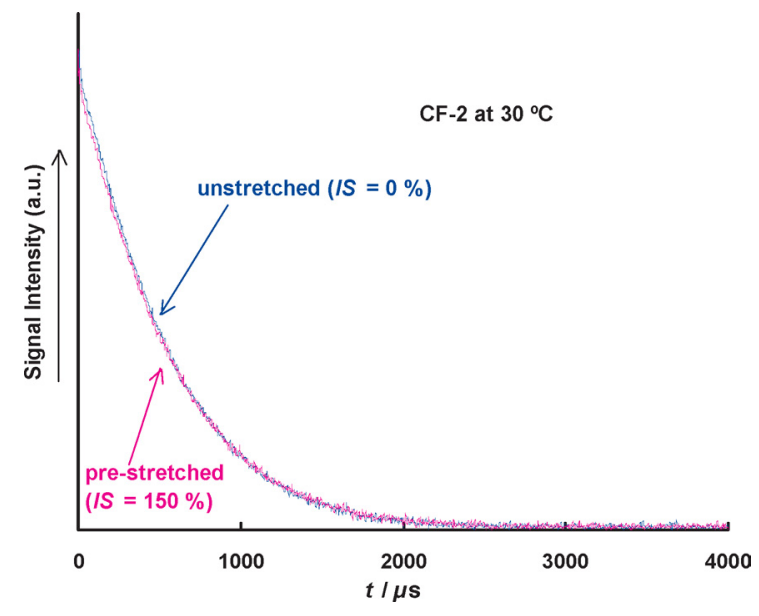

Figure 4. The FID signals at $30^{\circ} \mathrm{C}$ for carbon black filled SBR vulcanizate (CF-2) before (blue) and after (red) the tensile deformation.

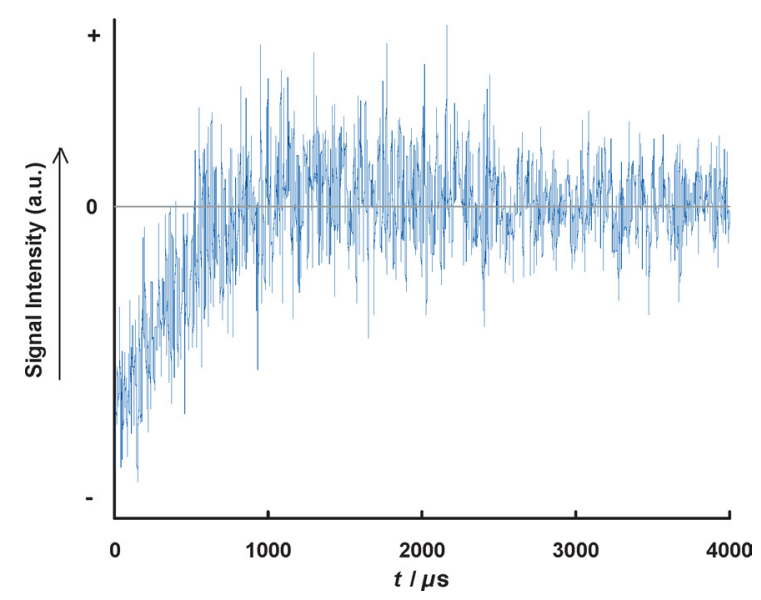

Figure 5. The subtracted FID signal for $\mathrm{CF}-2$.

restricted rubber molecules ${ }^{11-13)}$. Thus, the NMR results are expected to tell us which component will be involved in the chain scissions by a tensile force.

Figure 4 shows the free induction decay (FID) signals at $30^{\circ} \mathrm{C}$ for $\mathrm{CF}-2$ before $(I S=0 \%)$ and after $150 \%$ stretching $(I S=150 \%)$. The temperature of $30^{\circ} \mathrm{C}$ is well above the glass transition of $\operatorname{SBR}\left(T_{\mathrm{g}} \sim-52^{\circ} \mathrm{C}\right)$. Both FID signals could be decomposed into three components with different chain mobilities, the long $T_{2}\left(T_{2 \mathrm{~L}}\right)$, intermediate $T_{2}\left(T_{2 \mathrm{M}}\right)$ and short $T_{2}\left(T_{2 \mathrm{~S}}\right)$. Table 5 summarizes the $T_{2}$ data. It is seen that the $T_{2}{ }^{\prime} \mathrm{s}$ for $I S=0 \%$ are almost consistent with those for $I S=150 \%$ within an experimental error. This indicates that the chain mobility in each rubber phase was not affected by the tensile deformation. However, as seen in Fig. 4, the FID for $I S=0 \%$ was slightly different from that for $I S=150 \%$. As stated in the Experimental, the FID is a function of $T_{2}$ and the component fraction of each $T_{2}$. 
Table 6. $T_{2}{ }^{\prime} \mathrm{s}$ for surface modified silica filled vulcanizates with different $I S \mathrm{~s}$

\begin{tabular}{lcclccc}
\hline & \multicolumn{2}{c}{ DM-H } & & \multicolumn{2}{c}{ TM-1 } \\
\cline { 2 - 3 } \cline { 5 - 6 } \cline { 5 - 6 } & $I S=0 \%$ & $150 \%$ & & $0 \%$ & $150 \%$ \\
\hline$T_{2 \mathrm{~L}}(\mu \sec \pm 2 \%)$ & 532 & 542 & & 629 & 642 \\
$T_{2 \mathrm{M}}(\mu \sec \pm 7 \%)$ & - & - & & 253 & 228 \\
$T_{2 \mathrm{~S}}(\mu \sec \pm 22 \%)$ & 29.8 & 31.4 & & 20.7 & 20.0 \\
\hline
\end{tabular}

Thus, the results that the three $T_{2}$ 's were not affected by the tensile deformation (see Table 5) suggest that the difference of FID observed between $I S=0 \%$ and $I S=150 \%$ is induced by the change of component fraction. In order to confirm this, the FID for $I S=0 \%$ was subtracted from that for $I S=150 \%$ and the result is shown in Fig. 5. It is clearly seen that the signal intensity at shorter time region $(<1000 \mu \mathrm{sec})$ is negative, on the other hand, the intensity at longer time $(>1000 \mu \mathrm{sec})$ is positive. Unfortunately, the signal to noise ratio of the subtracted spectrum shown in Fig. 5 was too poor to calculate the $T_{2}$ and component fraction. However, it is true that the appearance of negative signal intensity at shorter time followed by the positive intensity at longer time is induced by the decrease of fast decay component and the increase of slow decay component. Judging from the decay time, it is speculated that the fast and slow decay components correspond, respectively to $T_{2 \mathrm{M}}$ and $T_{2 \mathrm{~L}}$. If so, the results shown in Fig. 5 suggest that a part of $T_{2 \mathrm{M}}$ component was converted into $T_{2 \mathrm{~L}}$ one by the tensile deformation. The results mean that the chain scissions occur preferentially at a restricted rubber phase. As a result, the broken rubber molecules were incorporated into a loosely restricted rubber phase, leading to the decrease of $T_{2 \mathrm{M}}$ component and the increase of $T_{2 \mathrm{~L}}$ component. The CF-1 also showed similar NMR results (data not shown) for the $\mathrm{CF}-2$ although the difference of FID signals between $I S=0 \%$ and $I S=150 \%$ was slightly small compared with the case of $\mathrm{CF}-2$, which might be responsible for the difference of characteristics of carbon black used in the study.

The FID subtraction technique mentioned above was utilized for silica filled samples to correlate with ESR results. Silica filled vulcanizates also showed three $T_{2}{ }^{\prime} \mathrm{s}$ at $30^{\circ} \mathrm{C}, T_{2 \mathrm{~L}}, T_{2 \mathrm{M}}$ and $T_{2 \mathrm{~S}}$. Although the origin of $T_{2 \mathrm{~S}}$ has been discussed in some literatures ${ }^{28-30}$, the details are still uncertain. We reported that the content of filler-gel in silica filled vulcanizates prepared by mechanical mixing was very small ${ }^{31,32)}$. As a result, the rubber phase in the silica filled vulcanizates was mainly composed of rubber-gel and free rubber. Table 6 summarizes the $T_{2}$ data for the TM-1 and DM-H with different $I S \mathrm{~s}$. The $T_{2 \mathrm{M}}$ component was not found in the DM-H. The DM-H was prepared by using

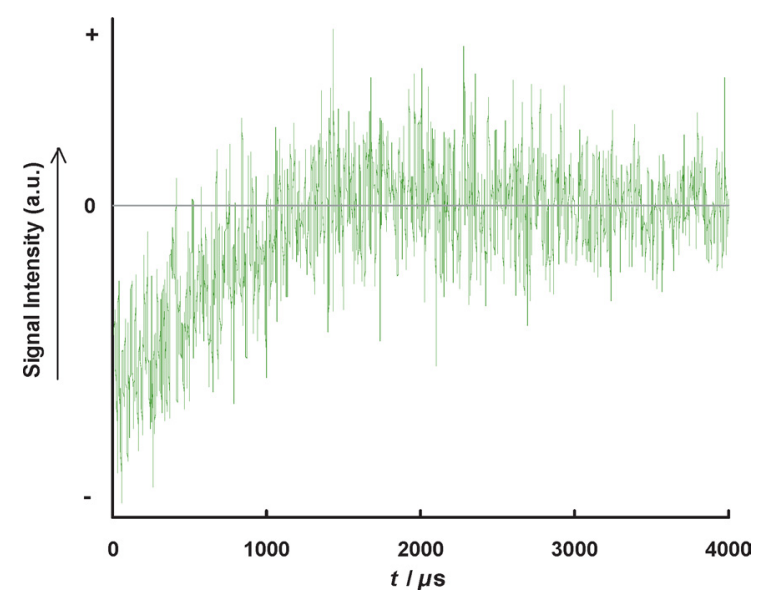

Figure 6. The subtracted FID signal for TM-1.

mono-functional coupling agent and there was no chemical interaction between rubber molecules and silica, which suggests that the chain mobility of the $T_{2 \mathrm{M}}$ component is similar to that of $T_{2 \mathrm{~L}}$ component. On the other hand, the TM-1 was prepared by using $b i$-functional coupling agent which produced the chemical couplings between rubber molecules and silica, resulted in the restricted molecular mobility in the $T_{2 \mathrm{M}}$ component. It is seen that both $T_{2 \mathrm{M}}$ and $T_{2 \mathrm{~L}}$ were not affected by the tensile deformation, similar to the case of carbon black filled samples. Thus, the FID for $I S=0 \%$ of TM-1 was subtracted from that for $I S=150 \%$ of TM-1 and the result is shown in Fig. 6. The signal intensity at shorter time $(<1000 \mu \mathrm{sec})$ is negative; on the other hand, the intensity of longer time $(>1000 \mu \mathrm{sec})$ is positive, similar to the case of carbon black filled samples. On the other hand, for the DM-H, the signal intensity after the subtraction was almost zero (data not shown). The results combined with the data shown in Table 6 indicate that the structural changes of each rubber phase in the DM$\mathrm{H}$ are negligibly small even after the extension of $150 \%$ strain.

As seen in Fig. 3, the degree of chain scissions at a $150 \%$ strain was extremely large for the TM-1 compared with that for DM-H. These NMR and ESR results indicate that the chain scissions occur primarily in the restricted rubber phase ( $T_{2 \mathrm{M}}$ component). Such component might correspond to the interfacial region produced by the chemical coupling between filler and rubber molecules. Gent found that the formation of small cavitations around the fillers during the tensile deformation of rubber matrix with fillers was enhanced by the existence of interfacial bondings ${ }^{33)}$. Such cavitations might enhance the stress concentration around the fillers during stretching, resulted in the chain scissions of rubber molecules. 


\section{Conclusions}

Filled SBR vulcanizates with different rubber/filler interactions were prepared by using several kinds of surface modified silicas and carbon blacks. Based on the ESR and pulsed NMR results, effects of rubber/filler interactions on structural changes of rubber matrix were investigated in relation to the chain scissions during the tensile deformation. The following conclusions were derived from experimental results;

1. For silica filled SBR vulcaniztaes, the degree of chain scission during tensile deformation of the samples could be evaluated from ESR data.

2. Information on the destruction of rubber matrix by a tensile force for both silica and carbon black filled SBR vulcanizates could be obtained from NMR results.

3. The stronger the interfacial bondings between filler and rubber matrix, the larger the degree of chain scission during tensile deformation of filled SBR vulcanizates that could be observed. Such chain scissions are suggested to occur in the interfacial regions between fillers and rubber molecules.

\section{References}

1) Mullins L.: Rubber Chem. Technol., 21, 281 (1948).

2) Harwood J. A. C, Mullins L., Payne A. R.: Rubber Chem. Technol., 39, 814 (1966).

3) Roland C. M.: J. Rheol., 33, 659 (1989).

4) Kilian H. G., Strauss M., Hamm W.: Rubber Chem. Technol., 67, 1 (1994).

5) Bueche F.: J. Appl. Polym. Sci., 10, 107 (1960).

6) Bueche F.: "Reinforcement of Elastomers", Ed. Kraus G., Interscience, New York, (1965), p. 1.

7) Yatsuyanagi F., Suzuki N., Ito M., Kaidou H.: Polymer, 42, 9523 (2001).

8) Yatsuyanagi F., Suzuki N., Ito M., Kaidou H.: Polym. J., 34, 332 (2002).
9) Yamaguchi K., Busfield J. J. C., Thomas A. G.: Polym. Sci. B, 41, 2079 (2003).

10) Suzuki N., Ito M., Yatsuyanagi F.: Polymer, 46, 193 (2005),

11) Pliskin I., Tokita N.: J. Appl. Polym. Sci., 16, 173 (1972).

12) Serizawa H., Ito M., Kanamoto T., Tanaka K., Nomura A.: Polym. J., 14, 149 (1982).

13) Serizawa H., Nakamura T., Ito M., Tanaka K., Nomura A.: Polym.J., 15, 201 (1983)

14) Goerl U., Hunsche A., Mueller A., Koban H. G.: Rubber Chem. Technol., 70, 608 (1997).

15) Suzuki N., Yatsuyanagi F., Ito M., Kaidou H.: J. Appl. Polym. Sci., 86, 1622 (2002).

16) DeVries K. L.: J. Polym. Sci. C, 32, 325 (1971).

17) Kaufman S., Bunger D. J. J.: Magnetic Resonance, 3, 218 (1970).

18) Wagner M. P.: Rubber Chem. Technol., 49, 703 (1976).

19) Hirata Y.: Nippon Gomu Kyokaishi, 59, 450 (1986).

20) Dannenberg E. M.: Rubber Chem. Technol., 59, 512 (1986).

21) Brennan J. J., Jermyn T. E.: Rubber Chem. Technol., 40, 817 (1967).

22) Lin C. J., Hergenrother W. L., Alexanian E., Böhm G. G. A.: Rubber Chem. Technol., 75, 865 (2002).

23) Ohonishi S., Ikeda Y., Sugimoto S., Nitta I.: J. Polym. Sci., 41, 503 (1960).

24) Carstensen P.: Makromol. Chem., 135, 219 (1970).

25) Carstensen P.: Makromol. Chem., 142, 131 (1971).

26) Collins R. L., Bell M. D., Kraus G.: J. Appl. Phys., 30, 56 (1959).

27) Fujimoto K., Inomata I., Fujiwara S.: Nippon Gomu Kyokaishi, 46, 232 (1973).

28) Ito M., Nakamura T., Tanaka K.: J. Appl. Polym. Sci., 30, 3493 (1985).

29) Ono S., Kiuchi Y., Sawanobori J., Ito M.: Polym. Int., 48, 1035 (1999).

30) Sawanobori J., Ono S., Ito M.: Kobunshi Ronbunshu, 47, 356 (2000).

31) Suzuki N., Ito M., Ono S.: Kaut. Gummi Kunstst., 57, 303 (2004).

32) Unagami R., Ito M., Ono S.: Nippon Gomu Kyokaishi, 77, 9 (2004).

33) Gent A. N.: J. Mater. Sci., 19, 1947 (1984). 